\title{
Important emerging bacterial zoonotic infections affecting the immunocompromised
}

\author{
Rosalie T. TREVEJO*, Margaret C. BARR, Robert Ashley ROBINSON \\ College of Veterinary Medicine, Western University of Health Sciences, Pomona, CA 91766, USA
}

(Received 17 September 2004; accepted 17 January 2005)

\begin{abstract}
The immunocompromised are at particular risk for infection with zoonotic diseases. Persons can be temporarily immunocompromised due to pregnancy or developmental stage (i.e. infants); longer-term or permanent states of immunosuppression can occur as a result of immunosuppressive treatment following cancer or organ transplant, or from infectious diseases, such as AIDS. The focus of this review article is on emerging bacterial zoonotic diseases that are of particular concern among the immunocompromised. Factors that affect disease emergence can include factors such as human demographics and behavior; technology and industry; economic development and land use; international travel and commerce; microbial adaptation and change; and breakdown of public health measures. The immunocompromised need to take precautions when engaging in seemingly normal activities such as food preparation; caring for companion animals; and recreational or occupational activities. The immunocompromised are not only more susceptible to infection, but often suffer more serious sequelae as a result of infection. This review article provides an overview of the major foodborne, respiratory, and vector-borne bacterial pathogens that affect the immunocompromised. The major categories of immunodeficiency are described. In addition, measures that can be taken to prevent infection, including the role of health education, are discussed.
\end{abstract}

zoonoses / emerging diseases / immunocompromised / bacterial / disease prevention

Table of contents

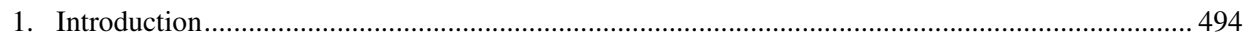

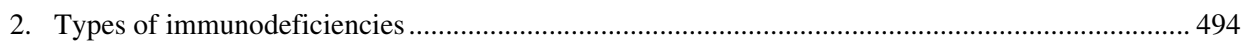

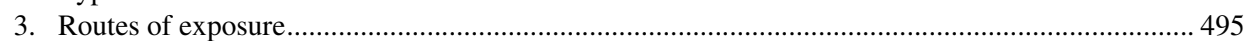

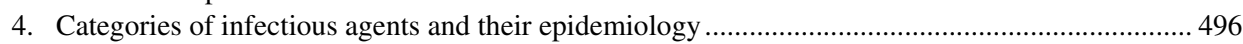

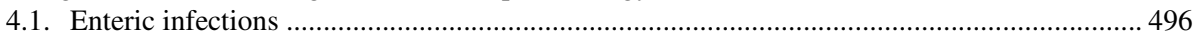

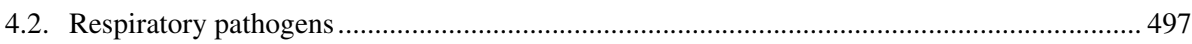

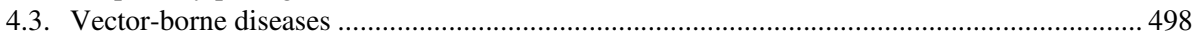

4.4. Diseases from animal bites and scratches or other contact .....................................................499

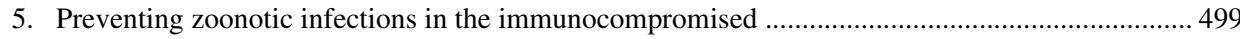

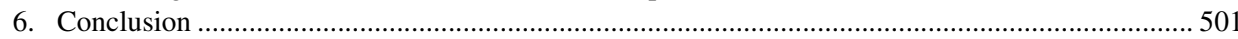

\footnotetext{
* Corresponding author: rtrevejo@westernu.edu
} 


\section{INTRODUCTION}

The Institute of Medicine defines emerging infections as those whose incidence in humans has increased within the past two decades due to factors such as changes in human demographics and behavior; technology and industry; economic development and land use; international travel and commerce; microbial adaptation and change; and breakdown of public health measures [54]. In some cases, there is an increased recognition of emerging diseases due to improvements in surveillance and/or detection methods (i.e. diagnostics). In addition to new human pathogens or those with increased potential for human exposure, due to changing lifestyles or demographics, some bacterial infections have escalated or re-emerged because of an increase in individuals with suppressed immune systems. This review article focuses on the major emerging bacterial zoonotic diseases in the immunocompromised. For purposes of this discussion, the immunocompromised are those at an increased risk of disease from, or more severely affected by, certain infectious agents compared to those that are immunocompetent.

Immune system abnormalities can be characterized as disorders affecting production or functionality of one or more cellular components. These include antibody (B cell) deficiency; cellular (T cell) deficiency; combined (B and T cell) immunodeficiency; or phagocytic dysfunction [34]. Immunodeficiencies arise due to either primary (genetic) or secondary (acquired) causes. Population-based data related to the incidence and prevalence of primary immunodeficiencies is needed [60]. The minimum estimate of birth prevalence of recognized severe combined immunodeficiency is $1 / 100000$, which is an underestimate due to infant deaths occurring before birth [23]. The proportion of the population living with acquired immunodeficiencies has increased due to the global HIV/AIDS epidemic, life-prolonging treatment of immunodeficiency diseases, and the use of chemotherapeutic agents and immunosuppressive drugs in cancer and transplantation patients [31]. In addition, the very young, the elderly, and pregnant women are generally not considered fully immunocompetent. Population estimates of acquired immunodeficiencies are more difficult to find in the published literature, and will be limited by differences in the duration and severity of the various immunocompromising conditions. A study based on estimates of organ transplant recipients and patients with human immunodeficiency virus infection, acquired immunodeficiency syndrome or cancer estimated that $3.6 \%$ of the USA population has an acquired immunodeficiency that renders them more susceptible to opportunistic diseases [57]. When pregnant women and the elderly are included in addition to the above populations, the proportion of the USA population with some degree of immunodeficiency is closer to $20 \%[42,94]$.

\section{TYPES OF IMMUNODEFICIENCIES}

The primary immunodeficiencies include severe X-linked defects and the primary autosomal deficiencies. Defects in B lymphocyte maturation, as seen with X-linked agammaglobulinemia, are characterized by an absence of mature B cells and immunoglobulins of all isotypes. Patients suffer from recurrent bacterial infections and septicemias with polysaccharide-encapsulated microorganisms such as pneumococci and Haemophilus influenzae [31, 53, 89]. Patients with $\mathrm{T}$ cell maturation defects have increased susceptibility to infections with intracellular bacteria such as Mycobacterium avium in addition to polysaccharide-encapsulated bacteria [31,53]. With X-linked severe combined immunodeficiency syndromes (SCID), both cytotoxic and helper T cells are absent because maturation of $\mathrm{T}$ lymphocytes is interrupted at an early stage. The lack of helper T cells results in defects in B cell responses to $\mathrm{T}$-dependent antigens and increased susceptibility to a broad range of bacterial infections [53]. 
The primary autosomal immunodeficiencies include DiGeorge syndrome, Type II bare lymphocyte syndrome, and many others $[31,53]$. Both DiGeorge syndrome and Type II bare lymphocyte syndrome result in SCID-like diseases caused by a dysfunction or lack of $\mathrm{T}$ helper cells. Infections with environmental or opportunistic bacterial pathogens are commonly seen in persons with these syndromes [53]. Some primary immunodeficiency disorders are not immediately clinically apparent. Complex genetic interactions increase the susceptibility of affected persons to development of certain immunoglobulin deficiency diseases [89]. Primary immunodeficiencies also arise from a multitude of defects in phagocytes, chemotactic factors, and complement components. In these diseases, infections of the respiratory tract, skin and mucous membranes with extracellular bacteria, such as Staphylococcus aureus and Pseudomonas, are common [31, 53].

Although primary immunodeficiencies are often life-threatening, secondary immunodeficiencies are far more common causes of immune system dysfunction $[4,60]$. Secondary immunodeficiencies have several etiologies, including: (i) drug-associated suppression of bone marrow precursor cells, mature lymphocytes, and/or phagocytes; (ii) suppression due to infectious disease (HIV, malaria); (iii) suppression associated with metabolic diseases (diabetes mellitus); and (iv) physiologic immune suppression (nutritional deficiency, pregnancy, agerelated) $[4,31,53]$. Chemotherapy-related immunosuppression of bone marrow usually results in SCID-like conditions, with resulting bacteremias and sepsis caused by many gram-positive and gram-negative bacteria [31]. The HIV-associated damage to cell mediated immunity is profound in later stages of AIDS, with frequent opportunistic infections and increased susceptibility to intracellular microorganisms such as Mycobacterium avium and Bartonella spp. [31]. Persons infected with malaria will be immunocompromised due to defects in macrophage, dendritic cell, and $\mathrm{CD} 8+$
T cell function [107, 108]. Salmonella septicemias and altered responses to polysaccharides have been reported in malaria-infected individuals [108]. Protein and micronutrient deficiencies contribute to the increased susceptibility of infections in developing countries [4]. The immunosuppression of pregnancy results from increased levels of endogenous corticosteroids and progesterone. Infections with Listeria monocytogenes are of particular concern because of pregnancy-associated, temporary deficits in cell mediated immunity [31].

\section{ROUTES OF EXPOSURE}

People can be exposed to bacterial zoonotic pathogens through a variety of routes [43]. Many zoonotic bacterial infections are foodor waterborne in origin and pose a particular risk to the immunocompromised [42]. Probably the most likely setting for zoonotic disease transmission is in or around the household, where everyday activities such as food preparation, pet care, and gardening can potentially result in zoonotic disease transmission to the immunocompromised. For instance, foodborne pathogens, which are typically transmitted via the fecal-oral route, can contaminate meat, produce, and other food products $[43,102]$. Outdoor recreational activities, such as backpacking, swimming, and hunting may also present opportunities for exposure to zoonotic pathogens. Ingestion of or contact with river, stream, or lake water can potentially result in indirect exposure to animal urine or feces [103]. Persons who hunt also risk exposure to zoonotic pathogens through direct handling of animal carcasses or ingestion of contaminated tissue. Certain occupations, such as veterinary medicine, agriculture, or others with direct animal contact are at an increased risk of exposure to certain zoonotic pathogens. The specific route of exposure will be described separately for each of the pathogens discussed in the following sections. Knowledge of the settings in which 
transmission of zoonotic infections are most likely to occur can assist in formulating patient guidelines for prevention.

\section{CATEGORIES OF INFECTIOUS AGENTS AND THEIR EPIDEMIOLOGY}

\subsection{Enteric infections}

Salmonellosis: It has been estimated that approximately 1.4 million non-typhoidal salmonella infections occur in the United States annually, resulting in approximately 15000 hospitalizations and 400 deaths [112]. Infection of healthy adults with non-typhoidal Salmonella usually results in self-limiting gastroenteritis that does not require antibiotic therapy, but severe clinical consequences can include septicemia, arthritis, meningitis, and pneumonia [29, 87]. However, the very young, elderly, and immunocompromised are at increased risk of complications and death, even if the infecting dose is low [51]. Non-immunological host risk factors include gastric hypoacidity in infants, pernicious anemia, and sickle cell anemia. Underlying immunosuppression should be ruled out in patients presenting with non-typhoidal Salmonella bacteremia in the absence of gastroenteritis [22]. A recent study of extra-intestinal non-typhoidal Salmonella infections in infants ( $<$ one year) and children up to 15 years of age showed that immunocompromised states resulting from therapy for malignancies, corticosteroid use, and severe malnutrition as a consequence of congenital heart disease or chronic pulmonary disease were associated with increased mortality rates [92].

The most common vehicles for transmission of food-borne salmonellosis are meat, meat products, eggs, and egg products that are contaminated as a direct result of animal infection or fecal contamination during processing [75]. A multi-state survey of consumer food-handling practices found that the elderly ( $>60$ years old) were more likely to report consumption of undercooked eggs than any other risky food handling behavior, and reported more frequent consumption of undercooked eggs than did persons $<60$ years old [3]. In the United States, multi-drugresistant Salmonella species (especially S. typhimurium) first emerged in animals and was subsequently recognized in humans by direct epidemiological and temporal evidence [100]. The use of antimicrobial agents in animals and humans results in the emergence and dissemination of resistant bacteria which may then be passed through food chains to humans resulting in infections that are refractory to antimicrobial treatments [6]. Animal feeds are a major link in the food safety chain and there is evidence that several human outbreaks of salmonellosis originated from the use of salmonella-contaminated animal feed [30]. Other animal sources of human salmonellosis, such as reptiles and rodents, have also been implicated [26, 39, 41].

Campylobacteriosis: Campylobacter is the most common cause of bacterial gastroenteritis in the United States, causing an estimated 2.4 million human infections annually [66]. While the usual manifestation is an acute self-limiting gastroenteritis, severe infections and post-infectious sequelae such as Guillain-Barre syndrome and reactive arthritis do occur [1]. Immunocompromised hosts are at increased risk for recurrent and chronic infections with Campylobacter [74]. Approximately 100 people die of Campylobacter jejuni infections in the United States annually, the majority of which are infants, elderly, or immunosuppressed persons [2]. Risk factors for infection include consumption of poultry, and contaminated raw milk and water $[40,55]$. Direct zoonotic transmission of Campylobacter from contact with infected kittens, puppies, and livestock has also been documented [12].

Escherichia coli O157: Escherichia coli O157:H7 was first identified as a pathogen in 1982 in an outbreak of bloody diarrhea traced to hamburgers from a fast-food chain [79]. Since that time E. coli $\mathrm{O} 157$ has 
emerged as a major cause of foodborne illness in the United States, with an estimated 92000 cases in 1997 [66]. Young children and the elderly are particularly susceptible to hemolytic uremic syndrome, a severe sequelae of $E$. coli $\mathrm{O} 157$ infection [45]. The intestinal tract of healthy cattle serves as a reservoir of E. coli $\mathrm{O} 157$ [65]. In addition to undercooked hamburger, unpasteurized milk and apple cider, contaminated water, and fresh produce have been implicated as sources of infection $[12,15]$. A recent case control study showed that using immunosuppressive medication was a significant risk factor for infection [56].

Yersinia enterocolitica: Approximately 87000 cases of foodborne Yersinia enterocolitica infection were estimated to occur in 1987 [66]. Since special selective media are required for detection of $Y$. enterocolitica [12], it is possible that lack of detection may result in underreporting. Y. enterocolitica is a cause of febrile gastroenteritis, especially in infants and minority populations, although extra-intestinal infection does occur [76]. Bacteremia is especially likely in immunosuppressed individuals and in those with underlying metabolic and hematologic disorders, such as iron overload and sickle cell disease [16]. Swine are the most common reservoir, and raw or undercooked pork or pork products are the most likely vehicles for transmission [12].

Listeriosis: Listeria monocytogenes has emerged as an important foodborne pathogen, with an estimated 2000 infections in the United States in 1997 [66]. The epidemiology of listeriosis is typically characterized by sporadic cases [12]. However, since 1981, several large outbreaks have been attributed to foods of animal origin, such as undercooked chicken, hot dogs, delicatessen meats, unpasteurized cheese products, and seafood [88]. Listeria infections may cause gastroenteritis in otherwise healthy adults but severe invasive infection often occurs in immunocompromised individuals, including infants, pregnant women, and the elderly [12]. Abortion, stillbirth, and neonatal mortality can result from maternally-acquired infections. Neonatal infections, occurring 1-3 weeks after birth, often present with meningitis. Other populations at risk include adults with underlying disease such as cancer, HIV infection, chronic hepatic disorders, and diabetes [83]. Individuals at particular risk include those with abnormalities in T-cell-mediated immunity, such as patients with solid organ or bone marrow transplants who are receiving adrenal corticosteroids [80].

\subsection{Respiratory pathogens}

Bordetellosis: Bordetella bronchiseptica is a respiratory tract pathogen that is primarily responsible for kennel cough in dogs, snuffles in rabbits, and atrophic rhinitis in piglets [44]. Healthy dogs may carry small numbers of this bacterium in their oropharynx for variable lengths of time. B. bronchiseptica infection in humans is considered rare, but has been documented in both healthy and immunocompromised individuals [63, 98, 116]. Of nine HIV patients from whom B. bronchiseptica was isolated, respiratory illnesses ranged from mild upper respiratory tract infections to pneumonia [36]. Two of these persons had household contact with dogs prior to their illnesses, and one had household contact with cats. The disease is more likely to be severe in individuals who are immunocompromised, such as those with Hodgkin disease, cystic fibrosis, or HIV infection [16, 49]. In one case report, $B$. bronchiseptica was isolated four times over two years from a 79-yearold bronchopneumonia patient with rabbit contact [47]. Accidental aerosol exposure to canine intranasal B. bronchiseptica vaccine in a veterinary setting may also pose an infection risk, particularly to immunocompromised patients [14].

Mycobacterioses: The Mycobacterium tuberculosis complex includes M. tuberculosis and $M$. africanum primarily from humans, and $M$. bovis from cattle [12]. Human tuberculosis primarily due to Mycobacterium tuberculosis is emerging as one of the most 
important diseases affecting patients with primary immunodeficiencies, HIV/AIDS, as well as those undergoing immunosuppressive therapy following organ transplants [97]. The emergence of drug resistant tuberculosis has further exacerbated the problem of this disease [25]. For instance, multi-drug resistant strains of $M$. bovis were identified in a nosocomial outbreak among HIV-infected patients [18]. The Mycobacterium avian complex, which is widespread in the environment, has emerged as an important cause of disseminated opportunitistic disease in HIV-infected patients [12].

Rhodococcus pneumonia: Rhodococcus equi is an important cause of bronchopneumonia in young foals [67]. In recent years, it has emerged as an increasingly common, and frequently fatal, opportunistic pathogen of humans immunocompromised by HIV infection or immunosuppressive therapy $[61,73,115]$. The disease in these patients often mimics tuberculosis with the formation of cavitary, granulomatous pneumonia [61, 104]. Although $R$. equi is an equine pathogen, its zoonotic potential is still unclear. The organism is ubiquitous in soil, and most cases of $R$. equi infection in humans cannot be associated with direct contact with animals [61]. Two recent studies of virulence-associated antigens in isolates from human patients in Thailand and Hungary have determined that the infecting $R$. equi strains are more closely related to isolates from regional pigs than to strains from horses in these areas [64, 101]. Further investigation is needed to clarify the routes and reservoirs of $R$. equi infection in humans [101].

\subsection{Vector-borne diseases}

Lyme disease (borreliosis), ehrlichiosis, and bartonellosis are emerging diseases in the USA that are all caused by bacteria that naturally reside in both animal and arthropod hosts [113]. Lyme disease has not been described as disproportionately affecting the immunocompromised, although this popu- lation can be severely affected by other tickborne diseases. The number of ehrlichial species infecting humans and animals has increased in the past several decades [70]. Elderly patients infected with Anaplasma phagocytophilum, the agent of human granulocytic ehrlichiosis (HGE) [35], are more likely to have severe disease, which typically presents with influenza-like symptoms with variable degrees of anemia, thrombocytopenia, leukopenia, and elevated liver enzymes [113]. HGE has been reported in pancreas transplant recipients [105]. Prior immunosuppression was noted in 3 of 4 patients infected with Ehrlichia ewingii, a recently recognized agent of human ehrlichiosis [24]. Cat or dog ownership has not been found to be a risk factor for increased seroprevalence of antibodies to the agent of HGE among persons in Australia [93]. All individuals engaging in outdoor activities should take all necessary precautions to reduce their risk of tick exposure, particularly when engaging in outdoor activities in areas where infected ticks are prevalent [95].

Bartonella henselae is the causative agent of cat-scratch disease (CSD), a granulomatous lymphadenopathy that characteristically develops 1 to 3 weeks after a cat bite or scratch [77]. Although CSD has been recognized as a zoonotic disease for many years, $B$. henselae was not isolated and characterized until the early 1990s [77]. It was first isolated from HIV-infected individuals suffering from bacillary angiomatosis, a newly recognized disease characterized by cutaneous and subcutaneous, proliferative vascular lesions. $B$. henselae also has been associated with endocarditis and fever with bacteremia in AIDS patients; CSD in immunocompetent individuals; and bacillary angiomatosis in immunocompromised people, including transplant recipients [78]. Cats serve as reservoirs and vectors for both diseases, although fleas or ticks may also serve as vectors for $B$. henselae, at least in its animal hosts [48]. Transmission of $B$. henselae to humans probably is accomplished by mechanical transfer (via the cat's claws) of infected flea feces into 
scarified skin [19]. Additionally, Ixodes ricinus ticks removed from humans have been demonstrated to carry $B$. henselae and thus might play a role in transmission of this organism [86]. Bartonella quintana, the causative agent of trench fever, and the closely related $B$. bacilliformis, are also transmitted by arthropods [77]. Immunocompromised individuals, including AIDS patients and transplant recipients, are at risk for complications of infection with $B$. quintana, which has been associated with bacillary angiomatosis and peliosis hepatitis in these patients $[17,19,28,111]$. Humans are the only known non-arthropod reservoir for these two species of Bartonella, although monkeys have been infected experimentally with $B$. quintana [19].

\subsection{Diseases from animal bites and scratches or other contact}

Many bacterial pathogens can be transmitted through animal bites and, less frequently, scratches. B. henselae, often transmitted to humans by cat scratches, has already been discussed above because of the role of arthropod vectors in its transmission. Immunocompromised people are at greater risk for systemic complications of animal bite wounds, including endocarditis and meningitis [21]. Capnocytophaga canimorsus, formerly CDC group DF-2, is emerging as an important cause of dog bite wound-associated disease in splenectomized and cirrhotic patients, as well as those with other immunocompromising conditions [20, 46, $62,85]$. Consequences of $C$. canimorsus infections include sepsis, endocarditis, meningitis, disseminated intravascular coagulation, and hemolytic uremic syndrome. In addition to dog bites, some cases of $C$. canimorsus septicemias have been associated with cat bites and scratches, and others have been acquired through mucosal contact with dog or cat saliva [62, 71, 84, 85, 109].

Pasteurella multocida and other species of Pasteurella are also important dog and cat bite pathogens [52]. Sepsis, endocarditis, and osteomyelitis are more likely to occur in patients with compromised immune function [52, 68]. Non-bite exposure (scratches, mucosal contact) to dogs and cats has also been associated with Pasteurella bacteremia in immunocompromised people $[46,106]$.

Mycobacterium marinum, although rarely reported, is a newly emerging disease associated with fish tank or other marine exposure that threatens immunocompromised pet fish enthusiasts [8]. In immunocompetent adults, lesions associated with $M$. marinum are usually limited to soft tissue nodules or ulcers and, occasionally, localized tenosynovitis or osteomyelitis [33, 110]. More invasive or disseminated forms of $M$. marinum infections, including multiple abscesses, septic polyarthritis, diffuse granulomatous reactions, and disseminated osteomyelitis, have been reported in immunosuppressed individuals $[9,10,32,37,50$, 59].

\section{PREVENTING ZOONOTIC INFECTIONS IN THE IMMUNOCOMPROMISED}

Prevention of zoonotic bacterial infections depends on recognition of routes of transmission, important reservoirs, and risk factors for infection. Veterinarians play a critical role in educating clients and the public on the transmission and prevention of zoonotic diseases. Educational materials to inform clients of zoonotic disease risks, such as signs posted in waiting areas, brochures, and newsletters can be used to prompt immunocompromised clients to seek advice regarding their companion animals such as described in the website Pets are Wonderful Support (PAWS): http://www.pawssf.org. Similarly, immunocompromised persons with animal-associated occupation risks need to be made aware of appropriate precautions to take in the workplace.

Presumably, there is a very strong animal-human bonding, especially for persons 
who may feel isolated as a result of their illness. It is simply not realistic to expect persons that are immunocompromised to avoid all animal contact in order to eliminate the risk of direct zoonotic infections. For example, Spencer et al. showed that $45 \%$ of HIV infected patients owned pets, although $60 \%$ of these patients had been advised not to keep pets [96]. Many studies have demonstrated the human health benefits of the human-animal bond among immunocompromised patients [5]. For instance, a recent study demonstrated that AIDS patients who owned pets reported less depression that those who did not own pets [91].

Specific recommendations for the care of companion animals belonging to immunocompromised persons have been published [7, 43, 81]. If a person or family elects to have a companion animal, extra precautions are needed to ensure that unnecessary risks are minimized. Pets should be fed only a high-quality commercial food, and not fed raw meat or eggs. Pets should not be allowed access to non-potable water, such as surface water or in toilet bowls. Dog should be confined whenever possible and walked only on a leash to prevent hunting, coprophagia, and garbage eating. Immunocompromised patients who wish to acquire a new pet should avoid puppies or kittens, as they are more susceptible to enteric infection [82]. The Centers for Disease Control and Prevention's Healthy Pets, Healthy People website recommends avoiding dogs and cats $<6$ months old, as they are more likely to carry zoonotic diseases [27]. Routine preventive care for pets, including vaccinations, should be provided. Screening of healthy animals to detect fecal shedding of enteric pathogens is of limited value unless serial samples are collected. Erythromycin treatment is indicated in symptomatic dogs or cats with a positive Campylobacter culture, but antibiotic treatment for Salmonella-associated diarrhea is likely to prolong shedding $[13,38]$. Steps to control and prevent ectoparasite infestation are important, especially in areas where vector-borne diseases are endemic. Animals should be regularly checked for ectoparasites and treated with an appropriate ectoparasiticide.

Immunocompromised patients need to pay special attention to safe food-handling practices, such as proper cooking of meat and eggs, washing hands after handling raw meat or chicken, and washing cutting boards after use. Kendall et al. [58] used the Delphi process with a group of recognized food safety experts to identify key food-handling behaviors among pregnant women, infants, and young children. Avoidance of soft cheeses, raw or undercooked seafood, delicatessen salads and lunchmeats not reheated to at least $165^{\circ} \mathrm{F}$, unpasteurized dairy products, raw and undercooked eggs, and non-potable water for drinking and food preparation were identified as important for disease prevention in this population. Eventually, high-risk groups may be advised to consume irradiated meats, poultry, and other foods as the technology becomes more widely accepted [72].

Immunocompromised persons who come in contact with animals in public settings such as fairs, petting zoos, or schools should take precautions to prevent infection with zoonotic pathogens such as E. coli O157, Salmonella, and Campylobacter [11]. The National Association of State Public Health Veterinarians has published a Compendium of Measures to Prevent Disease and Injury Associated with Animals in Public Settings, which recommends that accessible hand-washing facilities be provided and that persons refrain from consuming food and beverages in animal areas [69]. Children that are immunocompromised should be carefully supervised to ensure that all appropriate precautions are taken. Contact with wild animals and non-human primates should be avoided. Animals utilized in special therapy programs, hospitals, and convalescent homes will encounter populations with a high proportion of immunocompromised patients. The Centers for Disease Control and Prevention recommends that animals participating in animals-assisted 
activities and resident animal programs be fully vaccinated for zoonotic diseases and be healthy, well-groomed, and negative for enteric parasites [90]. Surprisingly, no petrelated infections were identified in a 12month study of 284 Minnesota nursing homes [99]. Providing that appropriate measures are in place to prevent the transmission of zoonotic diseases, the benefits of animalassisted therapy clearly outweigh the risks [114].

\section{CONCLUSION}

While a number of emerging bacterial zoonoses can be transmitted directly or indirectly to immunosuppressed persons, adherence to guidelines for preventive health care, diet, management, and hygiene can greatly reduce the risk of zoonotic transmission. Veterinarians will continue to play a major role in the diagnosis, treatment, and preventive care of companion animals. In addition, they have an important role to play in client and public education, and in functioning as part of a public health team along with other health professionals. Physicians and other health care professionals can benefit from receiving accurate and current information on prevention of zoonotic diseases from members of the veterinary community. Future population-based studies on immunocompromised patients should greatly help in characterizing their specific risk factors for acquiring zoonotic infections and the epidemiology of the diseases that impact this population.

\section{REFERENCES}

[1] Allos B.M., Campylobacter jejuni infections: update in emerging issues and trends, Clin. Infect. Dis. 32 (2001) 1201-1206.

[2] Altekruse S.F., Tollefson L.K., Human campylobacteriosis: a challenge for the veterinary profession, J. Am. Vet. Med. Assoc. 223 (2003) 445-452.

[3] Alterkruse S.F., Yang S., Timbo B.B., Angulo F.J., A multi-state survey of consumer food- handling and food consumption practices, Am. J. Prev. Med. 16 (1999) 216-221.

[4] Ambrus J.L. Sr., Ambrus J.L. Jr., Nutrition and infectious diseases in developing countries and problems of acquired immunodeficiency syndrome, Exp. Biol. Med. 229 (2004) 464-472.

[5] American Veterinary Medical Association, AVMA guidelines for responding to clients with special needs. AVMA Committee on the Human-Animal Bond, J. Am. Vet. Med. Assoc. 206 (1995) 961-976.

[6] Anderson A.D., Nelson J.M., Rossiter S., Angulo F.J., Public health consequences of use of antimicrobial agents in food animals in the United States, Microb. Drug Resist. 9 (2003) 373-379.

[7] Angulo F.J., Glaser C.A., Juranek D.D., Lappin M.R., Regnery R.L., Caring for pets of immunocompromised persons, J. Am. Vet. Med Assoc. 205 (1994) 1711-1718.

[8] Aubry A., Chosidow O., Caumes E., Robert J., Cambau E., Sixty-three cases of Mycobacterium marinum infection: clinical features, treatment, and antibiotic susceptibility of causative isolates, Arch. Intern. Med. 162 (2002) 1746-1752.

[9] Barton A., Bernstein R.M., Struthers J.K., O'Neill T.W., Mycobacterium marinum infection causing septic arthritis and osteomyelitis, Br. J. Rheumatol. 36 (1997) 1207-1209.

[10] Bartralot R., Pujol R.M., Garcia-Patos V., Sitjas D., Martin-Casabona N., Coll P., Alomar A., Castells A., Cutaneous infections due to nontuberculous mycobacteria: histopathological review of 28 cases, Comparative study between lesions observed in immunosuppressed patients and normal hosts, J. Cutan. Pathol. 27 (2000) 124-129.

[11] Bender J.B., Shulman S.A., Reports of zoonotic disease outbreaks associated with animal exhibits and availability of recommendations for preventing zoonotic disease transmission from animals to people in such settings, J. Am. Vet. Med. Assoc. 224 (2004) 1105-1109.

[12] Benenson A.S., Control of communicable diseases mannual, American Public Health Association, Washington DC, 1995.

[13] Benson C.E., Palmer J.E., Bannister M.F., Antibiotic susceptibilities of Salmonella species isolated at a large animal veterinary medical center: a three year study, Can. J. Comp. Med. 49 (1985) 125-128.

[14] Berkelman R.L., Human illness associated with use of veterinary vaccines, Clin. Infect. Dis. 37 (2003) 407-414. 
[15] Besser R.E., Lett S.M., Weber J.T., Doyle M.P., Barrett T.J., Wells J.G., Griffen P.M., An outbreak of diarrhea and hemolytic uremic syndrome from Escherichia coli $\mathrm{O} 157: \mathrm{H} 7$ in fresh-pressed apple cider, JAMA 269 (1993) 2217-2220.

[16] Bottone E.J., Yersinia enterocolitica: the charisma continues, Clin. Microbiol. Rev. 10 (1997) 257-276.

[17] Boulouis H.J., Chang C.-C., Henn J.B., Kasten R.W., Chomel B.B., Factors associated with the rapid emergence of zoonotic Bartonella infections, Vet. Res. 36 (2005) 383-410.

[18] Bouvet E., Casalino E., Mendoza-Sassi G., Lariven S., Vallee E., Pernet M., Gottot S., Vachon F., A nosocomial outbreak of multidrug-resistant Mycobacterium bovis among HIV-infected patients. A case-control study, AIDS 7 (1993) 1453-1460.

[19] Breitschwerdt E.B., Kordick D.L., Bartonella infection in animals: carriership, reservoir potential, pathogenicity, and zoonotic potential for human infection, Clin. Microbiol. Rev. 13 (2000) 428-438.

[20] Brenner D.J., Hollis D.G., Fanning G.R., Weaver R.E., Capnocytophaga canimorsus sp. nov. (formerly CDC group DF-2), a cause of septicemia following dog bite, and C. cynodegmi sp. nov., a cause of localized wound infection following dog bite, J. Clin. Microbiol. 27 (1989) 231-235.

[21] Brook I., Microbiology and management of human and animal bite wound infections, Prim. Care 30 (2003) 25-39.

[22] Brown M., Eykyn S.J., Non-typhoidal Salmonella bacteraemia without gastroenteritis: a marker of underlying immunosuppression. Review Of cases at St. Thomas' Hospital 1970-1999, J. Infect. 41 (2000) 256-259.

[23] Buckley R.H., Advances in the understanding and treatment of human severe combined immunodeficiency, Immunol. Res. 22 (2000) 237-251.

[24] Buller R.S., Arens M., Hmiel S.P., Paddock C.D., Sumner J.W., Rikhisa Y., Unver A., Gaudreault-Keener M., Manian F.A., Liddell A.M., Schmulewitz N., Storch G.A., Ehrlichia ewingii, a newly recognized agent of human ehrlichiosis, N. Engl. J. Med. 341 (1999) 148-155.

[25] Cahn P., Perez H., Ben G., Ochoa C., Tuberculosis and HIV: a partnership against the most vulnerable, J. Int. Assoc. Physicians AIDS Care 2 (2003) 106-123.

[26] Centers for Disease Control and Prevention, Salmonella hadar associated with pet duck- lings - Connecticut, Maryland, and Pennsylvania, Morb. Mortal. Wkly Rep. 41 (1992) $185-187$.

[27] Centers for Disease Control and Prevention, National Center for Infectious Diseases, Healthy Pets Healthy People, Advice for People at Extra Risk, [on line] http://www.cdc.gov/ healthypets/extra_risk.htm [consulted 12/14/ 04].

[28] Chomel B.B., Boulouis H.J., Breitschwerdt E.B., Cat scratch disease and other zoonotic Bartonella infections, J. Am. Vet. Med. Assoc. 224 (2004) 1270-1279.

[29] Cohen J.I., Bartlett J.A., Corey G.R., Extraintestinal manifestations of Salmonella infections, Medicine 66 (1987) 349-388.

[30] Crump J.A., Griffin P.M., Angulo F.J., Bacterial contamination of animal feed and its relationship to human foodborne illness, Clin. Infect. Dis. 35 (2002) 859-865.

[31] Davy V., Immunocompromised persons and emerging infectious diseases, in: Lashley F.R., Durham J.D. (Eds.), Emerging infectious diseases - trends and issues, Springer Publishing Company, New York, 2002, pp. 303-324.

[32] Decostere A., Hermans K., Haesebrouck F., Piscine mycobacteriosis: a literature review covering the agent and the disease it causes in fish and humans, Vet. Microbiol. 99 (2004) 159-166.

[33] Dobos K.M., Quinn F.D., Ashford D.A., Horsburgh C.R., King C.H., Emergence of a unique group of necrotizing mycobacterial diseases, Emerg. Infect. Dis. 5 (1999) $367-$ 378.

[34] Dorland's Illustrated Medical Dictionary, 27th Edition, W.B. Saunders Co., Philadephia, 2004.

[35] Dumler J.S., Barbet A.F., Bekker C.P., Dasch G.A., Palmer G.H., Ray S.C. et al., Reorganization of genera in the families Rickettsiaceae and Anaplasmataceae in the order Rickettsiales: unification of some species of Ehrlichia with Anaplasma, Cowdria with Ehrlichia and Ehrlichia with Neorickettsia, descriptions of six new species combinations and designation of Ehrlichia equi and 'HE agent' as subjective synonyms of Ehrlichia phagocytophila, Int. J. Syst. Evol. Microbiol. 51 (2001) 2145-2165.

[36] Dworkin M.S., Sullivan P.S., Buskin S.E., Harrington R.D., Olliffe J., MacArthur R.D., Lopez C.E., Bordetella bronchiseptica infection in human immunodeficiency virusinfected patients, Clin. Infect. Dis. 28 (1999) 1095-1099. 
[37] Enzensberger R., Hunfeld K.P., ElshorstSchmidt T., Boer A., Brade V., Disseminated cutaneous Mycobacterium marinum infection in a patient with non-Hodgkin's lymphoma, Infection 30 (2002) 393-395.

[38] Fox J.G., Moore R., Ackerman J.I., Campylobacter jejuni-associated diarrhea in dogs, J. Am. Vet. Med. Assoc. 183 (1983) 1430-1433.

[39] Friedman C.R., Torigian C., Shillam P.J., Hoffman R.E., Heltzel D., Beebe J.L., Malcolm G., DeWitt W.E., Hutwagner L., Griffin P.M., An outbreak of salmonellosis among children attending a reptile exhibit at a zoo, J. Pediatr. 132 (1998) 802-807.

[40] Friedman C.R., Hoekstra R.M., Samuel M., Marcus R., Bender J., Shiferaw B., Reddy S., Ahuja S.D., Helfrick D.L., Hardnett F., Carter M., Anderson B., Tauxe R.V., Emerging Infections Program FoodNet Working Group, Risk factors for sporadic Campylobacter infection in the United States: A case-control study in FoodNet sites, Clin. Infect. Dis. 38 (2004) S285-S296.

[41] Fujita K., Murono K., Yoshioka H., Pet-linked salmonellosis, Lancet 2 (1981) 525.

[42] Gerba C.P., Rose J.B., Hass C.N., Sensitive populations: who is at the greatest risk? Int. J. Food Microbiol. 30 (1996) 112-123.

[43] Glaser C.A., Angulo F.J., Rooney J.A., Animalassociated opportunistic infections among persons infected with the human immunodeficiency virus, Clin. Infect. Dis. 18 (1994) 14-24.

[44] Goodnow R.A., Biology of Bordetella bronchiseptica, Microbiol. Rev. 44 (1980) 722738.

[45] Griffin P.M., Tauxe R.V., The epidemiology of infections caused by Escherichia coli 0157:H7, other enterohemorrhagic E. coli, and the associated hemolytic-uremic syndrome, Epidemiol. Rev. 13 (1991) 60-98.

[46] Guay D.R., Pet-assisted therapy in the nursing home setting: potential for zoonosis, Am. J. Infect. Control. 29 (2001) 178-186.

[47] Gueirard P., Weber C., Coustumier A.L., Guiso N., Human Bordetella bronchiseptica infection related to contact with infected animals: persistence of bacteria in host, J. Clin. Microbiol. 33 (1995) 2002-2006.

[48] Guptill L., Bartonellosis, Vet. Clin. North Am. Small Anim. Pract. 33 (2003) 809-825.

[49] Hewlett E.L., Bordetella species, in: Mandell G.L., Bennett J.E., Dolin R. (Eds.), Principles and practice of infectious disease, Churchill Livingston, Philadelphia, 2000, pp. 24142422.

[50] Ho P.L., Ho P., Fung B.K., Ip W.Y., Wong S.S., A case of disseminated Mycobacterium marinum infection following systemic steroid therapy, Scand. J. Infect. Dis. 33 (2001) 232233.

[51] Hohmann E.L., Nontyphoidal salmonellosis, Clin. Infect. Dis. 32 (2001) 263-269.

[52] Hombal S.M., Dincsoy H.P., Pasteurella multocida endocarditis, Am. J. Clin. Pathol. 98 (1992) 565-568.

[53] Hostoffer R.W., Disorders of host defense, in: Patrick C.C. (Ed.), Clinical Management of infections in immunocompromised infants and children, Lippincott Williams \& Wilkins, Philadelphia, 2001, pp. 3-32.

[54] Institute of Medicine, Factors in emergence, in: Lederberg J., Oaks S.A. (Eds.), Emerging infections: microbial threats to health in the United States, National Academy Press, Washington DC, 1992, pp. 34-112.

[55] Kapperud G., Skjerve E., Bean N.H., Ostroff S.M., Lassen J., Risk factors for sporadic Campylobacter infections: results of a casecontrol study in southeastern Norway, J. Clin. Microbiol. 30 (1992) 3117-3121.

[56] Kassenborg H.D., Hedberg C.W., Hoekstra M., Evans M.C., Chin A.E., Marcus R., Vugia D.J., Smith K., Ahuja S.D., Slutsker L., Griffin P.M., Emerging Infections Program FoodNet Working Group, Farm visits and undercooked hamburgers as major risk factors for sporadic Escherichia coli O157:H7 infection: data from a case-control study in 5 FoodNet sites, Clin. Infect. Dis. 38 (2004) S271-278.

[57] Kemper A.R., Davis M.M., Freed G.L., Expected adverse events in a mass smallpox vaccination campaign, Effective Clinical Practice, March/April 2002 [on-line] http:// www.acponline.org/journals/ecp/marapr02/ kemper.htm [consulted 26 July 2004].

[58] Kendall P., Medeiros L.C., Hillers V., Chen G., DiMascola S., Food handling behaviors of special importance for pregnant women, infants and young children, the elderly, and immune-compromised people, J. Am. Diet. Assoc. 103 (2003) 1646-1649.

[59] Lahey T., Invasive Mycobacterium marinum infections, Emerg. Infect. Dis. 9 (2003) 14961498.

[60] Lendegren M.L., Kobrynski L., Rasmussen S.A. et al., Applying public health strategies to primary immunodeficiency diseases: a potential approach to genetic disorders, Morb. Mortal. Wkly Rep. 53 (2004) 1-29.

[61] Linder R., Rhodococcus equi and Arcanobacterium haemolyticum: two "coryneform" bacteria increasingly recognized as agents of human infection, Emerg. Infect. Dis. 3 (1997) 145-153. 
[62] Lion C., Escande F., Burdin J.C., Capnocytophaga canimorsus infections in human: review of the literature and case report, Eur. J. Epidemiol. 12 (1996) 521-533.

[63] Lo Re V., Brennan P.J., Wadlin J., Weaver R., Nachamkin I., Infected brachial cleft cyst due to Bordetella bronchiseptica in an immunocompetent patient, J. Clin. Microbiol. 39 (2001) 4210-4212.

[64] Makrai L., Takai S., Tamura M., Tsukamoto A., Sekimoto R., Sasaki Y., Kakuda T., Tsubaki S., Varga J., Fodo L., Solymosi N., Major A., Characterization of virulence plasmid types in Rhodococcus equi isolates from foals, pigs, humans, and soil in Hungary, Vet. Microbiol 88 (2002) 377-384.

[65] Martin M.L., Shipman L.D., Wells J.G., Potter M.E., Hedberg K., Wachsmuth I.K., Tauxe R.V., Davis J.P., Arnoldi J., Tilleli J., Isolation of Escherichia coli $\mathrm{O} 157: \mathrm{H} 7$ from dairy cattle associated with two cases of hemolytic uremic syndrome, Lancet 2 (1986) 1043.

[66] Mead P.S., Slutsker L., Dietz V., McCaig L.F., Bresee J.S., Shapiro C., Griffin P.M., Tauxe R.V., Food-related illness and death in the United States, Emerg. Infect. Dis. 5 (1999) 607-625.

[67] Meijer W.G., Prescott J.F., Rhodococcus equi, Vet. Res. 35 (2004) 383-396.

[68] Morris J.T., McAllister C.K., Bacteremia due to Pasteurella multocida, South. Med. J. 85 (1992) 442-443.

[69] National Association of State Public Health Veterinarians, Compendium of measures to prevent disease and injury associated with animals in public settings, 2004, http://www. nasphv.org/83416/84501.html [consulted 9/ 14/04].

[70] Neer T.M., Breitschwerdt E.B., Greene R.T., Lappin M.R., Consensus statement on ehrlichial disease of small animals from the infectious disease study group of the ACVIM. American College of Veterinary Internal Medicine, J. Vet. Intern. Med. 16 (2002) 309_ 315.

[71] Ngaage D.L., Kotidis K.N., Sandoe J.A., Unnikrishnan Nair R., Do not snog the dog: infective endocarditis due to Capnocytophaga canimorsus, Eur. J. Cardiothorac. Surg. 16 (1999) 362-363.

[72] Osterholm M.T., Norgan A.P., The role of irradiation in food safety, N. Engl. J. Med. 350 (2004) 1898-1901.

[73] Perez M.G., Vassilev T., Kemmerly S.A., Rhodococcus equi infection in transplant recipients: a case of mistaken Identity and review of the literature, Transpl. Infect. Dis. 4 (2002) 52-56.
[74] Peterson M.C., Clinical aspects of Campylobacter jejuni infections in adults, West. J. Med. 161 (1994) 148-152.

[75] Rabsch W., Tschape H., Baumler A.J., Nontyphoidal salmonellosis: emerging problems, Microbes Infect. 3 (2001) 237-247.

[76] Ray S.M., Ahuja S.D., Blake P.A., Farley M.M., Samuel M., Fiorentino T., Swanson E., Cassidy M., Lay J.C., Van Gilder T., Emerging Infections Program FoodNet Working Group., Population-based surveillance for Yersinia enterocolitica infections in FoodNet sites, 1996-1999: higher risk of disease in infants and minority populations, Clin. Infect. Dis. 38 (2004) S181-S189.

[77] Regnery R., Tappero J., Unraveling mysteries associated with cat-scratch disease, bacillary angiomatosis, and related syndromes, Emerg. Infect. Dis. 1 (1995) 16-21.

[78] Resto-Ruiz S., Burgess A., Anderson B.E., The role of the host immune response in pathogenesis of Bartonella henselae, DNA Cell Biol. 22 (2003) 431-440.

[79] Riley L.W., Remis R.S., Helgerson S.D., McGee H.B., Wells J.G., Davis B.R., Hebert R.J., Olcott E.S., Johnson L.M., Hargrett N.T., Blake P.A., Cohen M.L., Hemorrhagic colitis associated with a rare Escherichia coli serotype, N. Engl. J. Med. 308 (1983) 681.

[80] Rivero G.A., Torres H.A., Rolston K.V., Kontoyiannis D.P., Listeria monocytogenes infection in patients with cancer, Diagn. Microbiol. Infect. Dis. 47 (2003) 393-398.

[81] Robinson R.A., Zoonoses and immunosuppressed populations, in: MacPherson C.N.L., Meslin F.X., Wandeler A.I. (Eds.), Dogs, Zoonoses and Public Health, CABI, New York, 2001.

[82] Robinson R.A., Pugh R.N., Dogs, zoonoses and immunosuppression, J. R. Soc. Health 122 (2002) 95-98.

[83] Rocourt J., Jacquet C., Reilly A., Epidemiology of human listeriosis and seafoods, Int. J. Food Microbiol. 62 (2000) 197-209.

[84] Rosenman J.R., Reynolds J.K., Kleiman M.B., Capnocytophaga canimorsus meningitis in a newborn: an avoidable infection, Pediatr. Infect. Dis. J. 22 (2003) 204-205.

[85] Sandoe J.A., Capnocytophaga canimorsus endocarditis, J. Med. Microbiol. 53 (2004) 245-248.

[86] Sanogo Y.O., Zeaiter Z., Caruso G., Merola F., Shpynov S., Brouqui P., Roault D., Bartonella henselae in Ixodes ricinus ticks (Acari: Ixodida) removed from humans, Belluno Province, Italy, Emerg. Infect. Dis. 9 (2003) 329-332. 
[87] Saphra I., Winter J.W., Clinical manifestations of salmonellosis in man. An evaluation of 7779 human infections at the New York Salmonella Center, N. Engl. J. Med. 256 (1957) 1128-1134.

[88] Schlech W.F. 3rd, Foodborne listeriosis, Clin. Infect. Dis. 31 (2000) 770-775.

[89] Schroeder H.W. Jr., Schroeder H.W. 3rd, Sheikh S.M., The complex genetics of common variable immunodeficiency, J. Investig. Med. 52 (2004) 90-103.

[90] Sehulster L., Chinn R.Y.W., Guidelines for Environmental Infection Control in HealthCare Facilities. 2003, Morb. Mortal. Wkly Rep. Recomm. Rep. 52 (2003) 1-42.

[91] Siegel J.M., Angulo F.J., Detels R., Wesch J., Mullen A., AIDS diagnosis and depression in the Multicenter AIDS Cohort Study: the ameliorating impact of pet ownership, AIDS Care 11 (1999) 157-169.

[92] Sirinavin S., Jayanetra P., Thakkinstian A. Clinical and prognostic categorization of extraintestinal nontyphoidal Salmonella infections in infants and children, Clin. Infect. Dis. 29 (1999) 1151-1156.

[93] Skerget M., Wenisch, Daxboeck F., Krause R., Haberl R., Stuenzner D., Cat or dog ownership and seroprevalence of ehrlichiosis, Q fever, and cat-scratch disease, Emerg. Infect. Dis. 9 (2003) 1337-1340.

[94] Smith J.L., Long-term consequences of foodborne toxoplasmosis: Effects on the unborn, the immunocompromised, the elderly, and the immunocompetent, J. Food Prot. 60 (1997) 1595-1611.

[95] Spach D.H., Liles W.C., Campbell G.L., Quick R.E., Anderson D.E., Fritsche T.R., Tickborne diseases in the United States, N. Engl. J. Med. 329 (1993) 936-947.

[96] Spencer L., Study explores health risks and the human/animal bond, J. Am. Vet. Med. Assoc. 201 (1992) 1669.

[97] St. Georgiev V., Infectious diseases in immunocompromised hosts, CRC Press, 1997.

[98] Stephanelli P., Mastrantonio P., Hausman S.Z., Guiliano M., Burns D.L., Molecular characterization of two Bordetella bronchiseptica strains isolated from children with coughs, J. Clin. Microbiol. 35 (1997) 1550 1555 .

[99] Stryler-Gordon R., Beall N., Anderson R.K., Facts and fiction: health risks associated with pets in nursing homes, J. Delta Society 2 (1985) 73-74.
[100] Swartz M.N., Human diseases caused by foodborne pathogens of animal origin, Clin. Infect. Dis. 34 (2002) S111-S122.

[101] Takai S., Tharavichitkul P., Takarn P., Khantawa B., Tamura M., Tsukamoto A., Takayama S., Yamatoda N., Kimura A., Sasaki Y., Kakuda T., Tsubaki S., Maneekarn N., Sirisanthana T., Kirikae T., Molecular epidemiology of Rhodococcus equi of intermediate virulence isolated from patients with and without acquired immune deficiency syndrome in Chiang Mai, Thailand, J. Infect. Dis. 188 (2003) 1717-1723.

[102] Tauxe R.V., Emerging foodborne diseases: An evolving public health challenge, Emerg. Infect. Dis. 3 (1997) 425-434.

[103] Theirmann, Leptospirosis: Current developments and trends, J. Am. Vet. Med. Assoc. 184 (1984) 722-725.

[104] Torres-Tortosa M., Arrizabalaga J., Villanueva J.L., Galvez J., Leyes M., Valencia M.E., Flores J., Pena J.M., Perez-Cecilia E., Quereda C., Prognosis and clinical evaluation of infection caused by Rhodococcus equi in HIV-infected patients: a multicenter study of 67 cases, Chest 123 (2003) 1970 1976 .

[105] Trofe J., Reddy K.S., Stratta R.J., Flax S.D., Somerville K.T., Alloway R.R., Egidi M.F., Shokouh-Amiri M.H., Gaber A.O., Human granulocytic ehrlichiosis in pancreas transplant recipients, Transpl. Infect. Dis. 3 (2001) 34-39.

[106] Tseng H.K., Su S.C., Liu C.P., Lee C.M., Pasteurella multocida bacteremia due to non-bite animal exposure in cirrhotic patients: report of two cases, J. Microbiol. Immunol. Infect. 34 (2001) 293-296.

[107] Urban B.C., Roberts D.J., Malaria, monocytes, macrophages and myeloid dendritic cells: sticking of infected erythrocytes switches off host cells, Curr. Opin. Immunol. 14 (2002) 458-465.

[108] Urban B.C., Roberts D.J., Inhibition of T cell function during malaria: implications for immunology and vaccinology, J. Exp. Med. 197 (2003) 143-151.

[109] Valtonen M., Lauhio A., Carlson P., Mulranen J., Sivonen A., Vaara M., Lahdevirta J., Capnocytophaga canimorsus septicemia: fifth report of a cat-associated infection and five other cases, Eur. J. Clin. Microbiol. Infect. Dis. 14 (1995) 520-523.

[110] Van Seymortier P., Verellen K., De Jonge I., Mycobacterium marinum causing tenosynovitis. "Fish tank finger", Acta Orthop. Belg. 70 (2004) 279-282. 
[111] Velho P.E., Cintra M.L., Uthida-Tanaka A.M., de Moraes A.M., Mariotto A., What so we (not) know about human bartonellosis? Braz. J. Infect. Dis. 7 (2003) 1-6.

[112] Voetsch A.C., Van Gilder T.J., Angulo F.J., Farley M.M., Shallow S., Marcus R., Cieslak P.R., Deneen V.C., Tauxe R.V., Emerging Infections Program FoodNet Working Group, FoodNet estimate of the burden of illness caused by nontyphoidal Salmonella infections in the United States, Clin. Infect. Dis. 38 (2004) S127-S134.

[113] Walker D.H., Barbour A.G., Oliver J.H., Lane R.S., Dumler J.S., Dennis D.T., Persing D.H., Azad A.F., McSweegan E., Emerging bacterial zoonotic and vector-borne diseases. Ecological and epidemiological factors, JAMA 275 (1996) 463-469.

[114] Waltner-Toews D., Zoonotic disease concerns in animal-assisted therapy and animal visitation programs, Can. Vet. J. 34 (1993) 54.

[115] Weinstock D.M., Brown A.E., Rhodococcus equi: an emerging pathogen, Clin. Infect. Dis. 34 (2002) 1379-1385.

[116] Woolfrey B.F., Moody J.A., Human infections associated with Bordetella bronchiseptica, Clin. Microbiol. Rev. 4 (1991) 243255 . 